\title{
Your chance to quiz a potential future UK health secretary
}

\section{David Payne}

The BMJ

The BMJ is co-hosting a UK general election hustings with representatives from the main political parties and is asking readers to join the debate by submitting questions.

Participants in the event, which will be streamed live from the British Library at 11 am on Tuesday 21 April, will include Jeremy Hunt, Conservative health secretary; Norman Lamb, Liberal Democrat health minister; Andy Burnham, Labour health spokesman; and Louise Bours, UKIP health spokeswoman and MEP.

This debate will provide a platform for the parties to explain their policies on health and care to an audience of professionals, practitioners, patients, and policy makers. After opening statements from the parties' spokespeople it will follow a Question Time format chaired by Sarah Montague, presenter of BBC Radio 4's Today programme.
You can submit questions for consideration in advance of the event in one of two ways:

- By responding to this article; or

- By emailing voices@bmj.com.

The debate is being organised by the Health Foundation, the Nuffield Trust, the King's Fund, the NHS Confederation, the BMA, the National Voices coalition of healthcare charities, and The BMJ.

Watch the debate live from 11 am on 21 April at www. healthdebate.net.

Cite this as: BMJ 2015;350:h1932

๑ B BMJ Publishing Group Ltd 2015 